\title{
Validación de la Escala Inventario de Estrategias de Afrontamiento, Versión Española de Cano, Rodríguez, García (2007), En el contexto de Panamá
}

Por:

Dra. Yolanda González W. Doctora en Enfermería. Universidad Nacional de Colombia. Profesora Titular. Departamento de Salud de Adultos, Facultad de Enfermería. Universidad de Panamá.

E-mail: yolamari22@ahoo.com

Magister Estelina Ortega de Gómez. Profesora Especia IV. Escuela de Estadística de la Facultad de Ciencias Naturales Exactas y Tecnología. Universidad de Panamá.

E-mail: estelinao@hotmail.com

Magister Rosa Castillo De Lemos. Profesora especial IV, Departamento de Salud de Adultos, Facultad de Enfermería, Universidad de Panamá.

E-mail: rcastillo294@gmail.com

Martha Whetsell PhD. Profesora Asociada de Enfermería. Lehman Collage, Bronx, New York.

Profesor Asociado Programa de Doctorado en Ciencias de Enfermería. CUNY.

E-mail: marweth@hotmail.com

Diamantina C. Cleghorn Spencer. MPH; PhD; Estudios Post Doctoral en Salud Pública Global.

Profesora Titular de Salud Pública del Departamento de Salud Pública. Facultad de Enfermería de Enfermería. Universidad de Panamá. E-mail: diacleghorn@ hotmail.com

\section{Resumen}

Las estrategias de afrontamiento son aquellos comportamientos y habilidades cognitivas utilizadas por las personas para afrontar o lidiar con demandas del ambiente interno y externo que son percibidos como estresantes. Las establecen las personas según su contexto situacional, y el objetivo es determinar la validez y confiabilidad del Inventario de Estrategias de Afrontamiento (Coping Strategies Inventory CSI), versión española de Cano García, F. J.; Rodríguez Franco, L.; García Martínez, J. (1989), en el entorno de Panamá.

El inventario aborda la conceptualización de afrontamiento según Lazarus, Richard S. desde la perspectiva de enfermería Roy, Sor Callista.

Este estudio psicométrico, descriptivo, transaccional que indaga aspectos teóricos y de medición con un muestreo por conveniencia a una muestra aleatoria de 200 estudiantes de Licenciatura en Ciencias de Enfermería de la Universidad de Panamá durante exámenes finales del II semestre del 2015. El inventario conformado por 40 ítems y una autoevaluación de la eficacia. Las validaciones se realizaron considerando 5 estudiantes por ítem, totalizando la muestra de 200 estudiantes seleccionados., Se realiza el análisis con el coeficiente Alfa de Cronbach (mide consistencia interna) y Análisis Factorial Exploratorio (mide validez de constructo).

Los resultados muestran un Alfa de Cronbach de 0,930. El análisis factorial arroja tres dimensiones: afrontamiento individual, busca ayuda en otros, y reprime y oculta sus sentimientos. La medida de adecuación de la muestra Kaiser-Meyer-Olkin (KMO) fue superior a 0.90. La prueba de esfericidad de Barlett resulta significativa (p-valor <0.001; contrasta la hipótesis nula: no existe relaciones entre variables). 
La investigación concluye que la validación y confiabilidad de la escala es excelente para el caso de Panamá. Por tanto, es considerado como un aporte metodológico importante favoreciendo estudios posteriores sobre la comprensión del afrontamiento que permitirá descubrir más sobre su significado.

Palabras clave: Estudiantes de Enfermería, Exámenes Universitarios, Estrés Fisiológico.

\title{
Validation of Coping Strategy Inventory Scale, Spanish Version By Cano, Rodríguez, Garcia (2007), for Panama Context.
}

\begin{abstract}
Coping strategies are those behaviors and cognitive abilities used by people to cope or deal with demands of the internal and external environment that are perceived as stressful. They are established by people according to their situational context, and the objective is to determine the validity and reliability of the Coping Strategies Inventory (CSI) a Spanish version of Cano Garcia, F.J.; Rodriguez Franco, L.; Garcia Martinez, J. (1989) in Panama's surroundings.
\end{abstract}

The inventory addresses the conceptualization of coping according to Lazarus Richard S. from the Callista Roy's nursing perspective.

This psychometric, descriptive and transactional study investigates theoretical and measurable aspects with a sampling by convenience to a random sample of 200 students of Bachelor of Science in Nursing at the University of Panama during final exams of the second semester of 2015. The inventory consists of 40 items, and a self-assessment of effectiveness. Validations were made considering 5 students per item, totaling the selected sample of 200. The analysis is performed with the Cronbach's Alpha coefficient (measuring internal consistency) and Exploratory Factor Analysis (measuring construct validity).

The results show a Cronbach's Alpha of 0,930. The factor analysis presents three dimensions: individual coping, seeks help in others, and represses and hides feelings. The Kaiser-Meyer-Olkin measure of sampling adequacy (KMO) was above 0,90. The Barlett sphericity test is significant ( $\mathrm{p}$-value $<0,001$; contrasting the null hypothesis: there are no relationships between variables).

The research concludes indicating that the validation and reliability of the scale is excellent for the case of Panama. It is considered as an important methodological contribution favoring further studies about the understanding of coping allowing to discover more about its meaning.

Key words: Nursing Students, Universities and Colleges Examinations, Stress Physiological. 


\section{Validação Da Escala Inventário De Estratégias De Afrontamento, Versão Em Espanhol De Cano, Rodríguez E García, No Contexto De Panamá}

Introdução: as estratégias de afrontamento são aqueles comportamentos e habilidades cognitivas utilizadas pelas pessoas para afrontar o lidar com demandas do ambiente interno e externo que são percebidos como stress antes. São estabelecidas pelas pessoas segundo o contexto situacional. Se pretende determinar a validade e confiabilidade do Inventário de Estratégias de Afrontamento (CSI, pelas siglas em inglês), versão em espanhol de Cano, Rodrigues e García (1989), no entorno de Panamá. O inventário aproxima a conceptualização de afrontamento segundo Richard Lazarus. Desde Enfermagem Sor Callista Roy.

Éumestudo metodológico psicométrico que indaga aspectos teóricos e de medição; a amostragem é por conveniência, a amostra aleatória de 200 estudantes de Bacharelado em Ciências de Enfermagem da Universidade de Panamá durante provas semestrais do II semestre do ano 2015. O inventário conformado por 40 enunciados, e um adicional, mede auto avaliação da eficácia. A validação se realiza com mínimo de 5 estudantes por enunciado. Se realiza análise com o coeficiente Alfa de Cronbach (mede consistência interna) e Análise Factorial Exploratório (mede validade do constructo).

Resultados: o Alfa de Cronbach foi de 0,930. A análise factorial deutrêsdimensões: afrontamento individual, procura ajudaemoutros e reprime e oculta os sentimentos. A medida de adequação da amostra KMO foi superior a 0,90. O teste de esfericidade de Barlett resulta significativo (p-valor <0,001; contrasta a hipótese nula: não existe relação entre variáveis).

Conclusões: a validade e confiabilidade da escala são excelentes para Panamá, considerando-se um aporte importante que favorece estudos sobre a compreensão do afrontamento que permitirá descobrir e conhecer o seu significado.

Palavras clave: Estudantes de Enfermagem, Exames Universitários, Estresse Fisiológico.

\section{Introducción}

\section{Aspecto teórico-conceptual}

En nuestro quehacer diario en el ámbito profesional y en el académico hemos podido advertir que diversas personas pueden estar expuestas a un mismo acontecimiento y presentar comportamientos o estrategias y respuestas diversas, siendo las respuestas independiente de las estrategias utilizadas y dependiendo ambas del contexto situacional específico del momento en el cual ocurra el acontecimiento pudiendo ser positiva o adaptativa para algunas personas e inefectiva para otras, el fenómeno que induce esa diversidad de respuesta es el estrés, posee perspectiva psicológica y fisiológica; siendo el mayor exponente de la perspectiva psicológica Richard Stanley Lazarus con su modelo estrés y afrontamiento, mostrando un abordaje transaccional y Hans Selye el máximo exponente del enfoque 
fisiológico, es oportuno recordar que en 1956 él introduje el término de estrés al campo de la salud.

La exposición constante a situaciones estresantes activa el afrontamiento como proceso y como mecanismo de adaptación. El estrés y el afrontamiento se convierten en foco de estudios científico a partir de los años setenta en la disciplina de psicología (Galán y Perona, 2001), en Enfermería los primeros estudios seminales acerca del afrontamiento lo realiza Johnson, J. en la década de los 70, otras que han realizado estudios contribuyendo al fortalecimiento del constructo afrontamiento son Roy, Callista con su Modelo de Adaptación (1970) y la teoría de rango medio: Proceso de Afrontamiento y Adaptación, basándose en las conceptualizaciones teóricas de Lazarus y Nyamathi, Adeline en 1989 (González Y, 2008).

El fenómeno de interés del presente artículo son las estrategias de afrontamiento se incursionará en su evaluación a través de instrumentos de medición, siendo el objetivo del presente artículo socializar los resultados de la validación de la escala Inventario de estrategias de afrontamiento (CIS), versión española de Cano, Rodríguez y García (2007), en el contexto de Panamá.

\section{El afrontamiento}

Se vislumbra al afrontamiento como un proceso, un constructo complejo y dinámico, estabilizador que promueve el ajuste de la persona frente a contextos situacionales evaluadas como estresantes. El afrontamiento se define como "aquellos procesos cognitivos y conductuales constantemente cambiantes que se desarrollan para manejar las demandas específicas, externas y/o externas, que son evaluadas como desbordantes de los recursos del individuo (Lazarus y Folkman, 1986; González Y, 2008; Morán, Landeros, González, 20009; Castaño y Del Barco, 2010; Macías, Orozco, Amaris y Zambrano, 2013; Rubio, Dumitrache, Cordón y Rubio-Herrera, 2016).

Esta definición de afrontamiento involucra: una perspectiva cognitiva-sociocultural en donde ocurren constantes evaluaciones y re-evaluaciones cognitivas producto de la interacción persona- entorno y la implementación de estrategias o comportamientos ante diversos contextos situacionales de bienestar y enfermedad; el proceso implica cambios en pensamientos, sentimientos y actos en la medida en que ocurre la interacción; y además limita el afrontamiento a situaciones de estrés psicológico, excluyendo pensamientos y conductas automáticas. La enfermera(o) en su rol profesional y académico experimenta y maneja a diario su afrontamiento y el de otros.

Para poder sobrevivir el ser humano debe distinguir entre una situación favorable y otra que implica peligro, es por ello que existen formas básicas de valoración de la evaluación cognitiva como proceso mental continuo, que determina las consecuencias que provoca en la persona una situación u acontecimiento específico. La evaluación cognitiva parte de que generalmente las personas quieren y desean saber todo lo que ocurre a su alrededor y como eso afecta su bienestar, siempre desde una perspectiva optimista; la interacción de los factores personales como el compromiso, los deseos, las creencias y las creencias en el control personal y las existenciales interaccionan entre sí y con el entorno determinando las 
evaluaciones cognitivas (Lazarus, Folkman; 1986). La evaluación cognitiva es evaluativa porque considera las repercusiones y consecuencias de los sucesos; posee dos fases: -la evaluación primaria, -la evaluación secundaria; el orden de aparición de ambas en el proceso evaluación no es importante, lo de primera y segunda no se relaciona con el orden de aparición.

La evaluación primaria se refiere a la valoración en la que se visualizan las consecuencias que tiene la situación para la persona (Bernal, Lemos, Medina, Opina y Torres, 2009). Existen tres clases: -irrelevante ocurre cuando la interacción entre la persona y el entorno no conlleva implicaciones, necesidad, valor o compromiso para la persona o las mismas no son de su interés. -benigno-positiva, ocurre cuando la interacción con la persona y el entorno, son valoradas por este como positivas, es decir preservan su dominio y bienestar, generan emociones como felicidad, alegría, amor, tranquilidad. -evaluaciones estresantes, aquí se incluyen las que significan daño/pérdida, amenaza y desafío. El daño o pérdida implica suceso con pérdida de compromisos importantes, son perjudiciales.

La amenaza son evaluaciones de pérdidas y daños que se pronostican que pueden ocurrir en un futuro, hay movimientos de estrategias de afrontamiento, provoca emociones negativas como ansiedad, miedo, mal humor; la amenaza disminuye al cambiar el significado de la situación. El desafío ocurre cuando existe valoración que indica las fuerzas que va a necesitar la persona para vencer en el afrontamiento, es importante en el proceso de adaptación, involucra movimiento de estrategias de afrontamiento, provoca emociones como impaciencia, regocijo, excitación.

La evaluación secundaria es aquella que ocurre cuando la persona estima los recursos de la cual dispone para evitar o reducir las consecuencias negativas de la situación específica, (Bernal, Lemos, Medina, Opina y Torres, 2009); esta depende de la evaluación estresante. Con respecto a la re-evaluación cognitiva, es una nueva evaluación de la situación y que es capaz de modificar la evaluación previa provocando el cambio ya sea aumentando o disminuyendo el estrés.

El estudio psicoanalítico del yo, considera al afrontamiento estructuralmente como un rasgo y como un estilo. Al hablar de rasgos se consideran las propiedades con las cuales cuenta la persona para ejecutar en diversas situaciones, al respecto Lazarus y Folkman (1986) señalan que entre ellos encontramos: la represión-sensibilización, el mal humor, el buen humor, afrontamiento de evitación o control-brusquedad; los estilos son las amplias, variadas y generalizadas formas de tipos específicos de personas, ejemplo el amigable, el poderoso, el irritable, el cooperador, el soñador, etc.

El afrontamiento posee dos componentes el estilo y las estrategias ambos aspectos interdependientes y a la vez complementarios. Según su función el afrontamiento puede ser clasificado desde;- La perspectiva teórica del proceso del yo; - En el marco de la toma decisiones; el estudio de estas perspectivas han sido liderizadas por múltiples autores, psicólogos entre ellos White (1974) desde el marco psicológico, Mechanic (1974) perspectiva socio-psicológica, Moos (1977), Cohen y Lazarus (1979) desde la perspectiva salud-enfermedad; Pearlin y Schooler (1978) desde el control situacional; Dill et al (1980) desde el bienestar. Lazarus y Folkman (1980) refieren que en base a las observaciones 
realizadas por George (1974), Kahn et al (1964), Mechanic (1962), Murphy (1974)., Murphy y Moriarty (1976); Lieberman y Mullan (1981), se proponen dos principales funciones del afrontamiento clasificándolos en: afrontamiento dirigido al problema y el afrontamiento dirigido a la emoción, (Lazarus y Folkman 1986).

El afrontamiento dirigido al problema, se utilizan actividades manipuladas orientadas a modificar, alterar, o tolerar el problema, ocurren cuando la evaluación cognitiva de la persona le indica que la situación es susceptible a cambios, aquí la persona define y busca la soluciones, alternativas, (Lazarus y Folkman, 1986; Macías, Madariaga y Amaris, 2013; Pascual, Conejero, Etxebarria, 2017). Las estrategias de afrontamiento dirigidas a la emoción, ocurren cuando existe evaluación de que no se puede hacer nada para modificar la situación de daño, amenaza o desafío e implica procesos que ayudan para regular o modificar la expresión exterior de cualquier emoción y la experiencia subjetiva provocada por el problema, favoreciendo actitudes y pensamientos pasivos asociados al distrés emocional por lo que estas personas no están protegidos por el estrés causado por la enfermedad, estas estrategias son: evitación, minimización, distanciamiento, atención selectiva, comparaciones positivas, extracción de valores positivos, (Macías, Madariaga y Amaris, 2013; Pascual, Conejero, Etxebarria, 2017).

\section{Estilos de afrontamiento}

Los estilos de afrontamiento son aquellas predilecciones que tienen las personas para enfrentar diversos acontecimientos y van a determinar el uso particular de algunas estrategias de afrontamiento, al igual de ello depende su estabilidad en el contexto situacional y su temporalidad, la clasificación propuesta por Caver et al; 1989 son: activo/pasivo-evitativo; adaptativo/des adaptativo; cognitivo/afectivo/conductual y (Rubio et al; 2016). Carr (2007), realiza una revisión de los instrumentos de estrategias de afrontamiento, encontrando lo que denominó estilos de afrontamiento, siendo estas: estilos de afrontamiento centrado en las emociones, estilos de afrontamiento centrado en la solución de problemas y estilos de afrontamiento basados en la evitación o replanteamiento.

\section{Estrategias de afrontamiento}

Existen diversas conceptualizaciones de las estrategias de afrontamiento, Lazarus y Folkman (1984) citado por Martínez, Piquera e inglés (2012), lo define como los esfuerzos o acciones cognitivos y conductuales (comportamientos) que realiza la persona para manejar las demandas externas (ambientales, estresores) o internas (estado emocional) y que son evaluadas como estresantes (exceden los esfuerzos de la persona). (Bernal, Lemos, Medina, Opina y Torres, 2009).

Las estrategias de afrontamiento son aquellos comportamientos y habilidades cognitivas utilizadas por las personas para lidiar con las demandas del ambiente interno (emocional), que son percibidos como estresantes (Lazarus y Folkman 1989; González, Y; 2008; Rubio, Dumitrache, Cordón-Pozo; Rubio- Herrera, 2016). Desde la perspectiva de Enfermería las estrategias de afrontamiento son patrones innatos y adquiridos de las formas de manejar y responder al ambiente cambiante en las situaciones críticas mediante comportamientos enfocados en alcanzar el dominio, la supervivencia, el crecimiento y la trascendencia (Roy, 2004). Al respecto González, Y. (2008), señala que estas estrategias o 
comportamientos responden al ambiente cambiante en situaciones de la vida diaria y los periodos críticos.

Carr (2007), Pag. 271) basado en revisiones de Zeinder y Endler (1996), señala la identificación de tres clases de estrategias de afrontamiento: -Las estrategias centradas en el problema: estas se utilizan en condiciones de estrés controlable; -Las estrategias centradas en las emociones: se utilizan cuando la persona percibe situaciones de estrés incontrolable; -Las estrategias basadas en la evitación: ocurre cuando la persona asume retrasar o suspender el afrontamiento activo con el fin de ordenar y recopilar recursos psicosociales, para afrontar en forma activa (Macías et al. 2013).

Lazarus y Folkman (1986) con su perspectiva cognitivo sociocultural; Blanco, A (1995); Muela, Torres y Peláez,( 2002) proponen las estrategias de afrontamiento individual (con influencia social, aquí a persona define su propia orientación para manejar los acontecimientos), al reconocer que emerge de la interacción recíproca (persona-contexto) y de la rutina que exige la toma de decisiones, aquí Blanco retoma postulados del interaccionismo simbólico, que parte de que en la medida la persona pertenece a un contexto socio-cultural es participante activo de una realidad, generando o creando representaciones mentales significativas direccionados a la adaptabilidad de una estrategia y su eficacia considerando el contexto (Macías et al. 2013). Lazarus y Folkman (1986), introducen la Reevaluación como una estrategia o forma de afrontamiento cognitivo, y corresponde a los cambios introducidos en la evaluación inicial que busca cambiar el significado de la situación sin cambiarla objetivamente.

A continuación, algunos instrumentos Para evaluar las estrategias de afrontamiento, en la tabla 1 se concentran algunos.

Tabla 1. Instrumentos de Estrategias de Afrontamiento utilizados 1989 - 2016

\begin{tabular}{|c|c|c|}
\hline AÑO & AUTORES & INSTRUMENTO \\
\hline 1980 & $\begin{array}{l}\text { Richard Stanley Lazarus y Susan } \\
\text { Folkman }\end{array}$ & Ways of Coping Checklist (WCC) \\
\hline 1985 & $\begin{array}{l}\text { Vitaliano, Russo, Carr, Maiuro y } \\
\text { Becker }\end{array}$ & Ways of coping checklist \\
\hline 1989 & Tobin, Holroyd, Reynods y Kigel & Inventario de Estrategias de Afrontamiento (CSI) \\
\hline 1990 & Endler y Parker & Escala Multimodal Coping Inventory (MCI) \\
\hline 1992 & Rodríguez, Terol, López y Pastor & Cuestionario de formas de acontecimientos estresantes. \\
\hline 1992 & Pelechano & Cuestionario de estrategias de afrontamiento actuales \\
\hline 1993 & Charont Sandí & Escala de Estrategias de Afrontamiento-Revisado (EEC-R) \\
\hline 1994 & Chan D.W. & $\begin{array}{l}\text { Cuestionario Formas de afrontamiento: en estudiantes y } \\
\text { profesores de escuela secundaria. Versión China. }\end{array}$ \\
\hline 1994 & Amikhan & Indicador de estrategias de Afrontamiento \\
\hline 1997 & Crespo y Cruzado & $\begin{array}{l}\text { La Adaptación del inventario multidimensional de } \\
\text { Afrontamiento }\end{array}$ \\
\hline 1997 & Jiménez, Martin; Fernández-Abascal & Escala de Estilos y Estrategias de Afrontamiento. \\
\hline 1999 & $\begin{array}{l}\text { Solelo y Maupome. Ibáñez y Olmedo } \\
\text { (2003) }\end{array}$ & Escala de Modos de afrontamiento (EMA) \\
\hline 2002 & Canesa & Escala de Afrontamiento para adolescentes. \\
\hline 2004 & López y Marvan & Escala de Afrontamiento frente a Riesgos Extremos. \\
\hline
\end{tabular}


Enfoque, Revista Científica de Enfermería, VOL. XXI, N 17 Julio a Diciembre 2017 ISSN 1816-2398 Impreso

\begin{tabular}{|l|l|l|}
\hline 2006 & $\begin{array}{l}\text { Lodoño, Nora; Henao, Gloria; Puerta, } \\
\text { Isabel; Posada, Sara; Arango, Diana; } \\
\text { Aguirre, Daniel. }\end{array}$ & $\begin{array}{l}\text { Propiedades psicométricas y Validación de la Escala de } \\
\text { Estrategias de Coping modificada (EEC-M) en una muestra } \\
\text { Colombiana. }\end{array}$ \\
\hline 2007 & Cano, Rodríguez y García & $\begin{array}{l}\text { Adaptación española de Inventario de Estrategias de } \\
\text { Afrontamiento. (Versión de 40 enunciados) }\end{array}$ \\
\hline 2007 & Addison et al. & $\begin{array}{l}\text { Inventario de Estrategias de Afrontamiento. } \\
\text { (versión corta de dieciséis enunciados) }\end{array}$ \\
\hline 2008 & Ryrode, K, R; Petterson S y Otoole, S. & $\begin{array}{l}\text { Escala de formas de Afrontamiento: medición en educación } \\
\text { y psicología. }\end{array}$ \\
\hline 2009 & $\begin{array}{l}\text { Londoño. Nora; Pérez, Manuel, } \\
\text { Murillo María. }\end{array}$ & $\begin{array}{l}\text { Validación de la Escala de Estilos y Estrategias de } \\
\text { Afrontamiento. }\end{array}$ \\
\hline 2014 & $\begin{array}{l}\text { Rodríguez, Francisco; Estrada- Pineda, } \\
\text { Cristina; Rodríguez, Luis; Bringas- } \\
\text { Molledas, Calorina }\end{array}$ & $\begin{array}{l}\text { Adaptación del Inventario de Estrategias de Afrontamiento } \\
\text { (CSI) a la población penitenciaria de México. }\end{array}$ \\
\hline 2016 & $\begin{array}{l}\text { Dumitrate; Rubio; Gordón Pozo y } \\
\text { Rubio- Herrera }\end{array}$ & $\begin{array}{l}\text { Propiedades psicométricas de la versión española del } \\
\text { Inventario de Estrategias de Afrontamiento en adultos } \\
\text { mayores. }\end{array}$ \\
\hline
\end{tabular}

Fuente: González, Y (2017). Producto de la revisión o análisis conceptual de: Londoño, Nora et al. (2006); Londoño, Pérez y Murillo (2009); Nova, Carlos et al (2010); Cano, Rodríguez; García. (2007); Rubio, Laura et al (2016).

\section{Evaluación metodológica}

Richard Stantey Lazarus y Susan Folkman, crean la Escala Modos de Afrontamiento (Ways of Coping- Checklist, (WCC), 1980), desde entonces otros investigadores han elaborado escalas, cuestionarios e inventarios para la valoración de las estrategias de afrontamiento derivándolos de la escala original con cierto grado de variación. Los instrumentos que evalúan las estrategias de afrontamiento presentan características similares: -Parten de una situación estresante específica, -Evalúan estrategias efectivas y no efectivas a la vez, -No cuestionan lo que piensa o hace la persona normalmente, -Se ciñen a una situación específica, -Todos parten de considerar al afrontamiento como un constructo multidimensional, -Consideran la coexistencia entre el afrontamiento dirigido al problema y el dirigido a la emoción.

Carr (2007), realiza una revisión de los instrumentos de evaluación de las estrategias de afrontamiento encontrando que poseen: -Propiedades psicométricas buenas y moderadas, -Poseen subescalas que evalúan estrategias centradas en la emoción, en el problema y basados en la evitación; él denomina esta propiedad estilos de afrontamiento encontrándolos en instrumentos aportados por Endler y Parker (1990); Fergunson y Cox (1997); Folkman y Lazarus (1988); Moos (1993); Caver, Scheier y Weintraub (1989); Paterson y MCubbin (1987).

El estado del arte del afrontamiento devela la expansión del estudio de este fenómeno, pero no su delimitación, encontrándose diversas interpretaciones según las perspectivas de múltiples autores, algunas están enfocadas en: -el afrontamiento partiendo de la existencia de demandas situacionales, -según su papel o función enfocadas a la solución del problema y enfocadas en la emoción, -personalidad, -influencias en las prácticas y predilecciones culturales, -estímulos y estrategias cognitivas del instrumento Pelechano, (1992), citado por Castaño y León del Barco, (2010).

Lo cierto es que el Inventario de estrategias adolece de una estructura factorial de base acerca de los componentes específicos de las estrategias de afrontamiento, debido a que 
se vislumbra desde diversas perspectivas teóricas (Skinner, Edge, Altman Sherwood, 2003; citados por; Rodríguez, Estrada, Rodríguez, Bringas, 2013), todas estas diversidades traen serias controversias. Los grupos factoriales del Inventario de estrategias de afrontamiento son diversos van de dos a ocho factoriales, al igual la cantidad de enunciados 2,1 que conforman cada grupo factorial Rexrode, Petersen; O" Toole", (2008); Nava,Ollua,Vega,y Soria, (2010). No existe unificación en cuanto al listado de las estrategias de afrontamiento, se ha encontrado que diversos investigadores han elaborado listas de estrategias con nombres y numeración propia, haciendo imposible la definición y frecuencia de las estrategias con el mismo nombre, pero siempre presentando similitudes conceptuales fundamentales con connotaciones diversas ya sea en el significado o en hechos.

Sumado a lo antes expuesto metodológicamente hablando el proceso de validación de las escalas psicológicos genéricas y específicas, para medir y valorar el afrontamiento y sus estrategias son complejos y presentan: -Diversas limitaciones, -diversidad de interpretaciones, - Su contextualización. Otro aspecto importante es que las pruebas que son propias del proceso de validación muchas veces dependen de las pruebas específicas que se acostumbra aplicar en una región determinada o lo que se acostumbra como resultado de la cultura poblacional, esta situación introduce la diversidad metodológica en la utilización de las pruebas de análisis, alejándose de la estandarización de prueba y dando la apertura a la variabilidad; otra limitación radica en que los instrumentos disponibles que evalúan las estrategias de afrontamiento responden a ciertas propiedades psicométricas del fenómeno de estudio pero no responden en forma simultánea al contexto total en donde ocurre el fenómeno y al contexto cultural en el cual se va a aplicar.

Las limitaciones de los procesos metodológicos de validación han sido objeto de estudio de varios autores entre ellos Luján-Tangarife; Cardona-Arias,(2015); RamadaRodilla; Jm; Serra-Pujadas, C; Delclós-Clanchet, GL, (2013); Carvajal, a; Centeno, C; Watson, R; Martínez, M, Rubiales, A S; (2011), quienes señalan que las limitaciones que presenta el proceso de construcción y validación de escalas de medición en salud están relacionadas con la ausencia de claridad en la comunidad científico - académica acerca de los criterios del fenómeno sujeto a evaluación y a la ausencia de consenso acerca de los métodos de construcción y validación a aplicar en estos procesos. Estas variabilidades en los procesos reducen la posibilidad de comparaciones entre poblaciones de diversos países, culturas e idiomas, obstruyendo el intercambio de información, impulsando el diseño de políticas públicas de salud inapropiadas Carvajal, Centeno, Watson, Martínez, Rubiales, (2011). Una limitante no metodológica es que al aplicar el instrumento la persona rememora la situación estresante y hasta tiene que describirla en detalle, lo que puede provocar alteraciones psicológicas.

\section{Instrumentos}

Para el presente estudio se seleccionó la escala Inventario de estrategias de afrontamiento, la adaptación española, versión Cano, Rodríguez y García; (2007) en el contexto panameño.

El afrontamiento se dirige a situaciones concretas, cuando los pensamientos, sentimientos y actuaciones de las personas apuntan a situaciones específicas y significativas 
y para comprenderlo y evaluarlo se necesita conocer lo que el individuo afronta, por tal razón los instrumentos que evalúan las estrategias de afrontamiento parten del relato de una situación estresante (contexto situacional).

El Inventario de Estrategias de Afrontamiento (CSI), versión de Tobin et al: (1978).

El Inventario de estrategias de afrontamiento es el instrumento más aplicado a nivel mundial. Tobin, Holroyd, Reynods y Kigal (1989), crearon la versión original en inglés, fue desarrollado a partir de la Escala Modos de Afrontamiento de Folkman y Lazarus, (1980), parte del relato de una situación estresante específica experimentada durante el último mes, está compuesto de 109 enunciados, más de la mitad fueron generados por autores y producto de entrevistas estructuradas, abiertas y sesiones de lluvia de ideas. Fue validado por Tobin et al; (1989), en muestra de estudiantes universitarios y sometido al análisis factorial jerárquico que dio lugar a los 72 enunciados que responden al $47 \%$ de la varianza; coeficientes alfa de Cronbach entre 0,72 y 0,94; presenta escala tipo Likert de cinco puntos, no hay respuestas correctas o incorrectas; sólo se evalúa lo que usted hizo, pensó o sintió en ese momento. Al final de la escala se presenta un enunciado adicional que mide el grado en que la persona manejó la situación.

Está compuesto por tres estructuras jerárquicas, la estrategia primaria que comprende ocho factores, cuatro secundarias y dos terciarias. Las estrategias primarias se observan en la Tabla 2.

\section{Tabla 2. DISTRUBUCIÓN DE LA ESTRUCTURA I: ESTRATEGIAS PRIMARIAS Y SU CARGA FACTORIAL SEGÚN TOBIN ET AL; (1978)}

\begin{tabular}{|c|c|c|c|}
\hline $\begin{array}{l}\text { ESTRATEGIAS DE LA } \\
\text { ESTRUCTURA I }\end{array}$ & DESCRIPCIÓN & ITEMS & $\begin{array}{c}\text { CARGA } \\
\text { FACTORIAL }\end{array}$ \\
\hline $\begin{array}{l}\text { Factor 1: } \\
\text { Resolución de problemas. }\end{array}$ & $\begin{array}{l}\text { Son estrategias cognitivas y conductuales } \\
\text { encaminadas a eliminar el estrés, modificando la } \\
\text { situación }\end{array}$ & $\begin{array}{l}65,57,33,41 \mathrm{y} \\
17 .\end{array}$ & 0,82 a 0,67 \\
\hline $\begin{array}{l}\text { Factor 2: } \\
\text { Autocrítica. }\end{array}$ & $\begin{array}{l}\text { Estrategia basada en la autoinculpación y la } \\
\text { autocrítica por la ocurrencia de la situación } \\
\text { estresante o su inadecuado manejo }\end{array}$ & $23,47,31,55,63$ & 0,87 a 0,79 \\
\hline $\begin{array}{l}\text { Factor 3: } \\
\text { Expresión emocional. }\end{array}$ & $\begin{array}{l}\text { Estrategias encaminadas a liberar las emociones } \\
\text { que acontecen en el proceso de estrés }\end{array}$ & $\begin{array}{c}27,19,59,43 \text { y } \\
51\end{array}$ & 0,74 a $0,46$. \\
\hline $\begin{array}{l}\text { Factor 4: } \\
\text { Pensamiento desiderativo. }\end{array}$ & $\begin{array}{l}\text { Estrategias cognitivas que reflejan el deseo de } \\
\text { que la realidad no fuera estresante }\end{array}$ & $\begin{array}{c}38,30,22,62 \text { y } \\
46\end{array}$ & 0,79 a 0,59 \\
\hline $\begin{array}{l}\text { Factor 5: } \\
\text { Apoyo Social. }\end{array}$ & $\begin{array}{l}\text { Estrategias referidas a la búsqueda de apoyo } \\
\text { emocional }\end{array}$ & $\begin{array}{c}12,36,44,60 y \\
52\end{array}$ & 0,74 a 0,65 \\
\hline $\begin{array}{l}\text { Factor 6: } \\
\text { Re-estructuración cognitiva. }\end{array}$ & $\begin{array}{l}\text { Estrategias cognitivas que modifican el } \\
\text { significado de la situación estresante }\end{array}$ & $\begin{array}{c}66,58,42,34 \text { y } \\
10\end{array}$ & 0,72 a 0,55 \\
\hline $\begin{array}{l}\text { Factor } 7 . \\
\text { Evitación de Problemas. }\end{array}$ & $\begin{array}{l}\text { Estrategias que incluyen la negación y evitación } \\
\text { de pensamientos o actos relacionados con el } \\
\text { acontecimiento estresante }\end{array}$ & $\begin{array}{l}29,21,53,13 \text { y } \\
69\end{array}$ & 0,67 a 0,44 \\
\hline $\begin{array}{l}\text { Factor8: } \\
\text { Retirada social. }\end{array}$ & $\begin{array}{l}\text { Estrategia de retirada de amigos, familiares, } \\
\text { compañeros y personas significativas asociadas } \\
\text { con la reacción emocional en el proceso } \\
\text { estresante }\end{array}$ & $\begin{array}{c}48,32,72,56, y \\
8\end{array}$ & 0,74 a 0,39 \\
\hline
\end{tabular}

Fuente: Cano García, F.J; Rodríguez Franco, L; García Martínez, J. (2007). Adaptación española del inventario de Estrategias de Afrontamiento 
Las ocho estrategias primarias, se reagrupan en cuatro estrategias secundarias las cuales mostramos en la tabla 3 .

\begin{tabular}{|c|c|c|}
\hline Estructura II & Descripción & Estrategia \\
\hline $\begin{array}{l}\text { 1.Manejo adecuado centrado en el } \\
\text { problema }\end{array}$ & $\begin{array}{l}\text { Refleja afrontamiento adaptativo centrado en el problema. } \\
\text { modifica la situación o modifica su significado. }\end{array}$ & $\begin{array}{l}\text { 1.Resolución de problemas } \\
\text { 2. Reconstrucción cognitiva }\end{array}$ \\
\hline $\begin{array}{l}\text { 2. Manejo adecuado centrado en la } \\
\text { emoción. }\end{array}$ & $\begin{array}{l}\text { Refleja un afrontamiento adaptativo centrado en el manejo } \\
\text { de las emociones que afloran en el proceso estresante. }\end{array}$ & $\begin{array}{l}\text { 1.Apoyo social } \\
\text { 2. Expresión emocional }\end{array}$ \\
\hline $\begin{array}{l}\text { 3. Manejo inadecuado centrado en el } \\
\text { problema }\end{array}$ & $\begin{array}{l}\text { Indica un afrontamiento desadaptativo centrado en el } \\
\text { problema; evitando las situaciones estresantes o } \\
\text { fantaseando sobre realidades alternativas pasadas, } \\
\text { presentes o futuras. }\end{array}$ & $\begin{array}{l}\text { 1.Evitación de problemas } \\
\text { 2.Pensamiento desiderativo }\end{array}$ \\
\hline $\begin{array}{l}\text { 4. Manejo inadecuado centrado en la } \\
\text { emoción }\end{array}$ & $\begin{array}{l}\text { Refleja el afrontamiento desadaptativo centrado en las } \\
\text { emociones, pero basado en el aislamiento, la autocrítica y } \\
\text { la autoinculpación. }\end{array}$ & $\begin{array}{l}\text { 1.Retirada social } \\
\text { 2.Autocrítica }\end{array}$ \\
\hline
\end{tabular}

Fuente: Cano, Rodríguez y García (2007). Adaptación española del inventario de Estrategias de Afrontamiento.

Urrego; Aragón; Combita; Mora. (2012). Descripción de las Estrategias de afrontamiento para padres con hijos con discapacidad cognitiva.

La escala de la estructura factorial del tercer orden se reagrupan en forma empírica en dos estrategias terciarias o componentes, observe la tabla 4, en cada componente de la estructura terciaria lo conforman cuatro estrategias.

\section{Tabla 4. ESTRATEGIAS TERCIARIAS DEL INVENTARIO DE ESTRATEGIAS DE AFRONTAMIENTO SEGÚN TOBIN ET AL; (1978)}

\begin{tabular}{|l|l|l|}
\hline Estructura III & Descripción & Estrategia \\
\hline 1.Manejo adecuado & $\begin{array}{l}\text { Indica esfuerzos activos y adaptativos } \\
\text { para compensar la situación estresante }\end{array}$ & $\begin{array}{l}\text { 1. Resolución de problemas } \\
\text { 2. Re-estructuración cognitiva } \\
\text { 3. Apoyo social } \\
\text { 4. Expresión emocional }\end{array}$ \\
& & $\begin{array}{l}\text { 1. Evitación del problema } \\
\text { 2. Pensamiento desiderativo } \\
\text { 2. Manejo inadecuado centrado en la } \\
\text { emoción. }\end{array}$ \\
& $\begin{array}{l}\text { Sugiere afrontamiento pasivo y } \\
\text { desadaptativo }\end{array}$ & 4. Autocrítica. \\
\hline
\end{tabular}

Fuente: Cano, Rodríguez y García (2007). Adaptación española del inventario de Estrategias de Afrontamiento.

Urrego; Aragón; Combita; Mora. (2012). Descripción de las Estrategias de afrontamiento para padres con hijos con discapacidad cognitiva.

El Inventario de Estrategias de Afrontamiento (CSI), versión Cano, Rodríguez y García (2007)

El estudio de Cano et. al. (2007), adapta la escala al español (de España) y lo valida, factorizando 40 enunciados resultantes en una estructura de estrategias primarias y ocho factores (comportamientos/estrategias), logran la explicación del $61 \%$ de la varianza; el coeficiente de consistencia interna oscila entre 0,63 y 0,89 ; no confirman la estructura de estrategias secundarias ni terciarias.

Los ajustes realizados fueron los siguiente, los enunciado 8 ("traté de ocultar mis sentimientos") y 56 ("oculté lo que pensaba y sentía") cargaron originalmente en el factor expresión emocional y en menor medida en el factor retirada social, disminuía la fiabilidad 
0,25 en el primer factor y 0,12 en el segundo factor el cual a la vez era negativo y teóricamente se incluían en el factor retirada social por lo tanto fueron asignados a este factor; realizado este ajuste los enunciados cargaron en los factoriales esperados según los aportes de Tobin et al; (1989), con mayores saturaciones significativas en el estudio de Cano et al (2007).

El factor o la estrategia de evitación de problemas compuesto por los enunciados 7,15, 23, 31 y 39 no pasó la prueba que concluye que la escala es válida y confiable, presentando alfa de 0,72 y 0,63 en este estudio y en el de Tobin et al; (1989). Observe la tabla 5, con la varianza y confiabilidad del inventario de estrategias de afrontamiento en tres estudios diferentes.

Estudios realizados por Nava et al; 2010; Rodríguez Díaz et al; (2014), con la versión de Cano et al; (2007), no pudo confirmar la estructura secundaria y terciaria.

Descripción: el Inventario de Estrategias de afrontamiento recoge dos tipos de información: - fase cualitativa, en su primera parte, la persona describe la situación estresante, experimentada durante el último mes, de aquí se puede descubrir nuevos significados de estrés o nuevas estrategias de afrontamiento, diferenciando estrategias de respuesta o resultado. - fase cuantitativa, esta segunda parte corresponde a un auto informe, se le pide a la persona que responda a la frecuencia de utilización de estrategias de afrontamiento específicas con base a la situación estresante planteada en la primera parte, según la escala likert que va de 0 a 4 ; en donde $0=$ en absoluto, $1=$ un poco, $2=$ bastante, $3=$ mucho, $4=$ totalmente. A continuación, la tabla 4. con los resultados de la fiabilidad para los factores o estrategias de la estructura primaria, en tres estudios, observe la variabilidad de los datos.

Tabla 5. ESTRUCTURA DE LAS ESTRATEGIAS PRIMARIAS; DESCRIPCIÓN, CONFIABILIDAD Y VALIDEZ PARA EL ESTUDIO DE TOBIN ET AL; (1989), CANO, RODRÍGUEZ Y GARCÍA (2007) Y RUBIO ET AL (2016)

\begin{tabular}{|c|c|c|c|c|c|c|c|c|}
\hline \multirow{2}{*}{$\begin{array}{l}\text { Estructura I, } \\
\text { estrategias } \\
\text { primarias }\end{array}$} & \multirow[t]{2}{*}{ Descripción } & \multirow[t]{2}{*}{ Enunciados } & \multicolumn{2}{|c|}{$\begin{array}{l}\text { Tobin et al } \\
\text { (1989) }\end{array}$} & \multicolumn{2}{|c|}{$\begin{array}{l}\text { Cano, } \\
\text { Rodríguez y } \\
\text { García (2007) }\end{array}$} & \multicolumn{2}{|c|}{$\begin{array}{l}\text { Rubio, Dumitrache, } \\
\text { Cordón y Rubio- } \\
\text { Herrera (2016) }\end{array}$} \\
\hline & & & Var. & Alfa & Var & Alfa & Var & Alfa \\
\hline $\begin{array}{l}\text { 1. Resolución de } \\
\text { problemas. }\end{array}$ & $\begin{array}{l}\text { Son estrategias cognitivas y } \\
\text { conductuales encaminadas a eliminar el } \\
\text { estrés, modificando la situación }\end{array}$ & $\begin{array}{l}1,9,17,25, \\
33 .\end{array}$ & $5 \%$ & 0,82 & $9 \%$ & 0.86 & .729 & ,88 \\
\hline $\begin{array}{l}\text { 2.Re-estructuración } \\
\text { cognitiva. }\end{array}$ & $\begin{array}{l}\text { Estrategias cognitivas que modifican el } \\
\text { significado de la situación estresante }\end{array}$ & $\begin{array}{l}6,14,22 \\
30,38\end{array}$ & $3 \%$ & 0,83 & $7 \%$ & 0,80 & ,523 & ,78 \\
\hline 3. Apoyo Social. & $\begin{array}{l}\text { Estrategias referidas a la búsqueda de } \\
\text { apoyo emocional }\end{array}$ & $\begin{array}{l}5,13,21,29, \\
37\end{array}$ & $6 \%$ & 0,89 & $8 \%$ & 0,80 & ,569 & ,79 \\
\hline $\begin{array}{l}\text { 4.Expresión } \\
\text { emocional. }\end{array}$ & $\begin{array}{l}\text { Estrategias encaminadas a liberar las } \\
\text { emociones que acontecen en el proceso } \\
\text { de estrés }\end{array}$ & $\begin{array}{l}3,11,19,27, \\
35 .\end{array}$ & $6 \%$ & 0,89 & $8 \%$ & 0,84 & .57 &, 86 \\
\hline $\begin{array}{l}\text { 5. Pensamiento } \\
\text { desiderativo. }\end{array}$ & $\begin{array}{l}\text { Estrategias cognitivas que reflejan el } \\
\text { deseo de que la realidad no fuera } \\
\text { estresante }\end{array}$ & $\begin{array}{l}4,12,20,28, \\
36 .\end{array}$ & $4 \%$ & 0,78 & $8 \%$ & 0,78 & ,592 &, 75 \\
\hline 6. Autocrítica. & $\begin{array}{l}\text { Estrategia basada en la autoinculpación } \\
\text { y la autocrítica por la ocurrencia de la } \\
\text { situación estresante o su inadecuado } \\
\text { manejo }\end{array}$ & $\begin{array}{l}2,10,18,26 \\
34\end{array}$ & $12 \%$ & 0,94 & $9 \%$ & 0,89 & ,730 & .87 \\
\hline $\begin{array}{l}\text { 7. Evitación de } \\
\text { Problemas. }\end{array}$ & $\begin{array}{l}\text { Estrategias que incluyen la negación y } \\
\text { evitación de pensamientos o actos } \\
\text { relacionados con el acontecimiento } \\
\text { estresante }\end{array}$ & $\begin{array}{l}7,15,23,31 \\
39\end{array}$ & $7 \%$ & 0,72 & $6 \%$ & 0,63 & ,371 & ,65 \\
\hline 8. Retirada social. & $\begin{array}{l}\text { Estrategia de retirada de amigos, } \\
\text { familiares, compañeros y personas }\end{array}$ & $\begin{array}{l}8,16,24 \\
32,40\end{array}$ & $4 \%$ & 0,81 & $5 \%$ & 0,65 &, 531 &, 72 \\
\hline
\end{tabular}




\begin{tabular}{|l|l|l|l|l|l|l|l|l|}
\hline & $\begin{array}{l}\text { significativas asociadas con la reacción } \\
\text { emocional en el proceso estresante }\end{array}$ & & & & & & & \\
\hline Para toda la escala & & & $47 \%$ & 0,72 y & $61 \%$ & 0,63 & & y \\
& & & 0,94 & 0,89 & & \\
\hline
\end{tabular}

Fuente: Cano, Rodríguez y García (2007). Rubio; Dumitrache; Cordón- Pozo; Rubio-Herrera. (2016)

Estudio confirmatorio de las estrategias secundarias y las estrategias terciarias por Rubio, Dumitrache, Cordón-Pozo y Rubio Herrera (2016),

Rubio, Dumitrache, Cordón-Pozo y Rubio Herrera (2016), llevan a cabo varias pruebas de análisis factorial confirmatorio, utilizando el paquete estadístico MPLUS 7.3 se utiliza un estimador para el análisis de datos categóricos.

Otros análisis estadísticos se realizaron con el paquete SPSS; el estudio reportó la validación de la estructura primaria, secundaria y la terciaria, utilizando el análisis de factores confirmatorio cuyo objetivo es verificar estas estructuras jerárquicas, en su estudio después de realizada varias pruebas, se decide eliminar de la escala el ítem 7 y el 39 ya que demostraron estandarización residual baja ( +4 en valores absolutos) y baja confiabilidad individual, Otro aspecto es que la comprensión de ambos enunciados al ser traducidos al español era similar; luego de retirarlos la confiabilidad del instrumento inventario subió a 0,74 con varianza de 0,5008 .

Metodología: se trata de una investigación metodológica, psicométrica, ya que indaga acerca de aspectos teóricos y aplicados a la medición, se realiza la validación y confiabilidad del Inventario de Estrategas de Afrontamiento, versión española de Cano, Rodríguez, García (2007), en el contexto de Panamá. en la población de estudiantes universitarios de la Facultad de Enfermería la cual fue de 639 estudiantes (Dirección de escuela de Enfermería, 2015). Se utilizó un muestreo por conveniencia seleccionando una muestra de 200 estudiantes de la carrera de Licenciatura en Enfermería, cursando el primero, segundo tercero y cuarto año, en situación estresante A pesar de ser una muestra por conveniencia la inclusión del estudiante al estudio fue aleatorio.

\section{Procedimiento}

El Inventario de estrategias de afrontamiento fue aplicado a cada estudiante durante la $1^{\mathrm{a}}$ primera semana de exámenes semestrales correspondientes al segundo semestre académico, al salir del aula posterior a la realización del examen, aplicando el instrumento autoadministrable tomándole aproximadamente 25 minutos para su llenado en un salón; previa lectura y firma de la hoja de consentimiento informado, a la vez se le brinda al estudiante una breve orientación acerca de lo que se investiga y se responde a preguntas, se les informa acerca de la confidencialidad de la información y la ausencia de respuestas incorrectas.

Para el análisis estadístico se utilizó el programa estadístico para ciencias sociales SPSS versión 20, para la validación y confiabilidad del instrumento en la población panameña, se aplican parámetros propuestos por Sánchez y Echeverry (2004); ajustándose 
en tres fases: primero la selección de la escala, segundo es la validez de apariencia y la fase tres las pruebas de validez y confiabilidad.

La primera fase fue la selección del instrumento, se realiza búsqueda en bases de datos, se aplican las siguientes palabras claves: instrumentos de afrontamiento, proceso de afrontamiento, estrategias de afrontamiento con abordaje teórico o conceptual, y con sus combinaciones en el título o resumen, publicaciones en español, inglés y portugués, y a la vez artículos de validación y confiabilidad de instrumentos o escalas en salud, encontrándose una gran variedad de artículos.

La segunda fase consistió en la validez de apariencia este no aplica concepto estadístico, y su finalidad es ver la aceptación de la escala en el contexto panameño, a través de juicios de expertos sobre la pertinencia de la escala y su aplicabilidad y aceptabilidad. El procedimiento fue el siguiente, se forman dos grupos, cinco (5) expertos docentes y el otro con cinco (5) estudiantes. Con respecto a los docentes tres (3) con título de Doctor y dos (2) con título de Maestría; cinco (5), estudiantes matriculados en el Programa de Maestría de Enfermería con énfasis en cardiovascular.

Con respecto a la validez de apariencia Paniagua (2015), señala que la validación de expertos va a definir si el instrumento mide la variable de estudio.

La tercera fase consistió en la medición de la consistencia interna del instrumento, la misma se mide a partir del coeficiente del alfa de Cronbach y para conocer si los datos mantienen la estructura se realiza la validez de constructo utilizando el análisis factorial exploratorio.

\section{Resultados}

La investigación se desarrolla en el mes de noviembre - diciembre 2015, los estudiantes universitarios de la carrera de Licenciatura de la Facultad de Enfermería, Universidad de Panamá, que participaron en el estudio, presentaron la siguiente distribución según nivel académico que cursaban. El grupo etario oscilo entre 18- 45 años. En la tabla 6 y gráfica 1 se evidencia distribución homogénea de estudiantes en los niveles evaluados

\begin{tabular}{l|c|c}
$\begin{array}{c}\text { Tabla 6. Distribución de la muestra } \\
\text { según nivel de estudios periodo } \\
\text { noviembre a diciembre } 2015\end{array}$ \\
\begin{tabular}{l|c|c} 
Nivel \\
Académico
\end{tabular} & Número & $\begin{array}{c}\text { Porcentaje } \\
(\%)\end{array}$ \\
\hline TOTAL & 200 & 100.00 \\
Primero & 53 & 26.50 \\
Segundo & 59 & 29.50 \\
Tercero & 48 & 24.00 \\
Cuarto & 40 & 20.00 \\
\hline
\end{tabular}
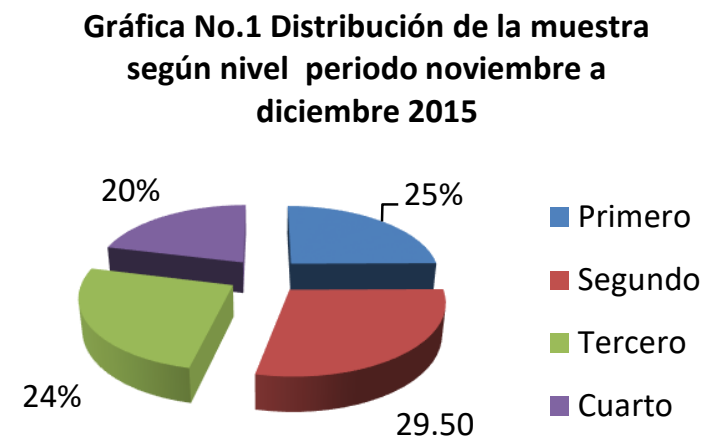

Fuente: González, Ortega, Castillo, Whetsell, Cleghorn

(2015). Información derivada de la aplicación del Inventario de Estrategias de Afrontamiento, durante el estudio. 
De los 200 estudiantes que participaron del estudio, el $15 \%$ (30) fueron hombre y el $85 \%$ (170) mujeres, observe la gráfica 2.

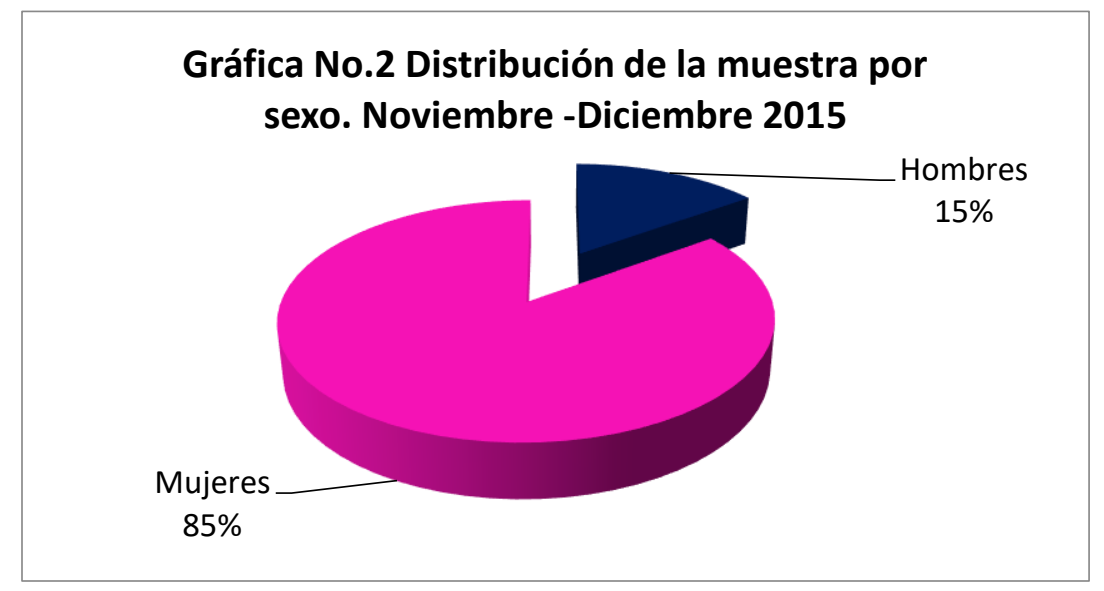

Fuente: González, Ortega, Castillo, Whetsell, Cleghorn (2015). Información derivada de la aplicación del Inventario de Estrategias de Afrontamiento, durante el estudio.

Para el proceso de validación fase 2, validez de apariencia, se realizó en el inventario los siguientes ajustes lingüísticos; sugeridos para el contexto panameño. Los cuales se detallan en la tabla 7.

Tabla 7. Ajustes lingüísticos para el inventario de estrategias de afrontamiento

\begin{tabular}{l|l}
\hline \multicolumn{1}{c|}{ ESTRATEGIA PRIMARIA/ ENUNCIADOS } & AJUSTES LINGUISTICOS SUGERIDOS \\
\hline Resolución de problemas. & \\
\hline $\begin{array}{l}\text { 9.Me esforcé para resolver los problemas de la } \\
\text { situación }\end{array}$ & 9. Me esforcé para resolver los problemas. \\
\hline Expresión emocional & \\
\hline 35. Mis sentimientos eran abrumadores y estallaron & $\begin{array}{l}\text { 35. Mis sentimientos me abrumaban y } \\
\text { estallaron. }\end{array}$ \\
\hline Pensamiento desiderativo & \\
\hline 4.Deseé que la situación nunca hubiera empezado & \begin{tabular}{l} 
4. Desee que la situación nunca se hubiera dado. \\
\hline Apoyo social
\end{tabular} \\
\hline 5. Encontré a alguien que escuchó mi problema. & $\begin{array}{l}\text { 5. Encontré a alguien a quien contarle mi } \\
\text { problema }\end{array}$ \\
\hline
\end{tabular}

Fuente: González, Ortega, Castillo, Whetsell, Cleghorn (2015). Información derivada de la aplicación del Inventario de Estrategias de Afrontamiento, durante el estudio.

\section{Fiabilidad}

Con respecto a la consistencia interna de la prueba se buscó a partir del coeficiente alfa de Cronbach el cual permite comprobar si el instrumento es confiable para el estudio y permitirá realizar mediciones estables o consistentes. Este análisis, basado en la homogeneidad estructural del instrumento, utiliza el coeficiente $\alpha$ (alfa) de Cronbach el cual está diseñado para instrumentos con cualquier escala de opciones múltiples y cuyo indicador es presentado como un parámetro de rango entre cero (0) a uno (1), a continuación, la categorización. 
Tabla 8. Categorización del Alfa de Cronbach

\begin{tabular}{|lll|}
\hline Coeficiente alfa & $>0.9$ & Es excelente \\
\hline Coeficiente alfa & $>0.8$ & Es bueno \\
\hline Coeficiente alfa & $>0.7$ & Es aceptable \\
\hline Coeficiente alfa & $>0.6$ & Es cuestionable \\
\hline Coeficiente alfa & $>0.5$ & Es pobre \\
\hline Coeficiente alfa & $<0.5$ & Es inaceptable
\end{tabular}

Fuente: George, D., \& Mallery, P. (2003). SPSS for Windows step by step: A simple guide and reference.

Al evaluar la fiabilidad total para la escala, se evidencia un alfa de Cronbach de 0,930 categorizándose como excelente para evaluar el constructo.

Tabla 9. Estadística de fiabilidad

\begin{tabular}{|c|c|}
\hline Alfa de Cronbach & $\mathrm{N}^{\circ}$ de elementos \\
\hline $\mathbf{0 , 9 3 0}$ & $\mathbf{4 0}$ \\
\hline
\end{tabular}

Tabla 10 demuestra la confiabilidad para los cuatro grupos factoriales resultantes de la estructura 1, presenta fiabilidad que oscila entre excelente a aceptable.

Tabla 10. Cuatro grupos factoriales resultantes de la estructura 1 del Inventario de Estrategias de Afrontamiento y sus Coeficiente alfa de Cronbach

\begin{tabular}{|c|l|c|l|c|}
\hline Factores & Estudio Actual & Ítems & \multicolumn{1}{|c|}{ Ítems por factor } & $\begin{array}{c}\text { Alfa de } \\
\text { Cronbach }\end{array}$ \\
\hline I & $\begin{array}{l}\text { Dirigido a la } \\
\text { emoción }\end{array}$ & 15 & $\begin{array}{l}1,2,3,4,8,9,10,11,12,15, \\
16,17,18,19,31\end{array}$ & 0.963 \\
\hline II & $\begin{array}{l}\text { Dirigido a la } \\
\text { solución de } \\
\text { problemas }\end{array}$ & 15 & $\begin{array}{l}5,6,7,13,14,21,22,25,27, \\
29,30,33,36,37,38\end{array}$ & 0.964 \\
\hline III & Evitación & 8 & $23,24,26,32,34,35,39,40$ & 0.883 \\
\hline IV & Reevaluación & 2 & 20,28 & 0.758 \\
\hline
\end{tabular}

Fuente: González, Ortega, Castillo, Whetsell, Cleghorn (2015). Información derivada de la aplicación del Inventario de Estrategias de Afrontamiento, durante el estudio.

Observe en la tabla 11, la variabilidad de las alfas para cada estrategia en tres estudios en los estudios. En el actual estudio el alfa oscilo entre excelente y bueno. 
Tabla 11. Comparaciones de alfas de Cronbach para los Factores o estrategias de afrontamiento del Inventario de estrategias en tres estudios

\begin{tabular}{|c|c|c|c|c|c|c|c|c|c|}
\hline \multirow[t]{2}{*}{$\begin{array}{l}\text { Factores o } \\
\text { estrategias }\end{array}$} & \multicolumn{3}{|c|}{ Estudio Actual 2015} & \multicolumn{3}{|c|}{$\begin{array}{l}\text { Cano, Rodríguez y } \\
\text { García (2007) }\end{array}$} & \multicolumn{3}{|c|}{$\begin{array}{l}\text { Navas; Ollua; Méndez, } \\
\text { Vega y Trujano (2010) }\end{array}$} \\
\hline & Ítems & Var. & Alfa & Ítems & Var. & Alfa & Ítems & Var. & Alfa \\
\hline $\begin{array}{l}\text { Resolución de } \\
\text { problema }\end{array}$ & 5 & $9 \%$ & 0.922 & 5 & $9 \%$ & 0.86 & 5 & $8 \%$ & 0.8 \\
\hline Autocritica & 5 & $8 \%$ & 0.84 & 5 & $9 \%$ & 0.89 & 5 & $9 \%$ & 0.86 \\
\hline $\begin{array}{l}\text { Expresión } \\
\text { emocional }\end{array}$ & 5 & $9 \%$ & 0.896 & 5 & $8 \%$ & 0.84 & 5 & $8 \%$ & 0.86 \\
\hline $\begin{array}{l}\text { Pensamiento } \\
\text { desiderativo }\end{array}$ & 5 & $9 \%$ & 0.898 & 5 & $8 \%$ & 0.78 & 5 & $8 \%$ & 0.84 \\
\hline Apoyo Social & 5 & $9 \%$ & 0.901 & 5 & $8 \%$ & 0.8 & 5 & $8 \%$ & 0.84 \\
\hline $\begin{array}{l}\text { Reestructuración } \\
\text { cognitiva }\end{array}$ & 5 & $9 \%$ & 0.922 & 5 & $7 \%$ & 0.8 & 5 & $7 \%$ & 0.82 \\
\hline $\begin{array}{l}\text { Evitación de } \\
\text { problemas }\end{array}$ & 5 & $9 \%$ & 0.884 & 5 & $6 \%$ & 0.63 & 5 & $7 \%$ & 0.7 \\
\hline Retirada social & 5 & $8 \%$ & 0.837 & 5 & $5 \%$ & 0.65 & 5 & $6 \%$ & 0.78 \\
\hline
\end{tabular}

Fuente: González, Cleghorn, Ortega, Castillo y Whetsell (2015). Información derivada de la aplicación del Inventario de Estrategias de Afrontamiento, durante el estudio.

\section{Validación: análisis factorial}

El análisis factorial como técnica estadística examina la matriz de correlación entre los enunciados o ítems, se utiliza como punto de partida para identificar grupos de enunciados que verifican que hay fuerte correlación entre ellos y los enunciados de un grupo con baja correlación entre ellos.

Para determinar si es aceptable la realización del Análisis Factorial, se aplica la Prueba de Esferidad Bartlett que permite plantear en la hipótesis nula que no existe correlación alguna entre las variables considerando un valor de significancia de $5 \%$. Posteriormente, la Prueba de Kaiser-Meyer-Olkin (KMO) evalúa si la muestra es adecuada para realizar un análisis factorial y donde su resultado puede oscilar entre 0 y 1.

Los datos obtenidos a través de la aplicación del Inventario de Estrategias de Afrontamiento se ajustan bien a las dimensiones obtenidas por el análisis factorial ya que la medida de adecuación muestral KMO es superior a 0,90. En cuanto a la prueba de esfericidad de Barlett resulta significativa (p- valor $<0,0001$; lo que se pone de manifiesto que no existe relación entre estas variables. Tabla 12 
Tabla12. Prueba de adecuación muestral KMO y de la prueba de Esfericidad de Barlett

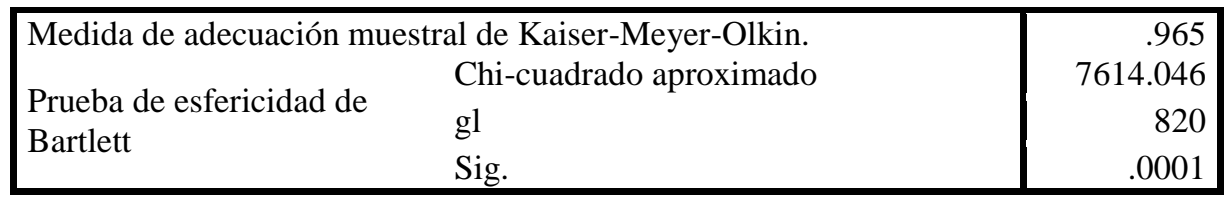

Fuente: González, Cleghorn, Ortega-Gómez, Castillo y Whetsell (2015). Información derivada de la aplicación del Inventario de Estrategias de Afrontamiento, durante el estudio.

En el análisis se logra la varianza explicada empleando el método de extracción de componentes principales con rotación Varimax, donde se obtuvo que los cuatro primeros componentes explican el $90 \%$ de la variabilidad.

El análisis factorial nos presenta una estructura primaria de cuatro componentes o grupos esta presentación nos lleva a nombrar toda la estructura como: "Estrategias de Afrontamiento Individual", fundamentando esta denominación en el uso de las estrategias de afrontamiento visibles a través de los comportamiento de las personas; el análisis conceptual de la propuesta de estructura que presentaron investigadores como Lazarus y Folkman (1986), con su modelo de Teoría de la evaluación cognitiva y a Blanco, Amalio (1995), en su teoría sociocultural y siendo máximo exponente de la psicología social al reconocer el surgimiento del afrontamiento de la interacción de la persona con su contexto sociocultural (Macías et al; 2013).

Lazarus y Folkman (1986) propone las estrategias de afrontamiento individual y Blanco, A. (1995), resalta la participación activa de la persona en su contexto. La designación del nombre "Estrategas de afrontamiento individual se debe a que el comportamiento de la estructura 1 producto del análisis factorial del actual estudio se apoya en la perspectiva teórico conceptual de Lazarus y Folkman quienes presenta la propuesta, de la estrategia de afrontamiento individual como el producto de la interacción recíproca de la persona con su contexto y la rutina que demanda de la persona la toma de decisiones; esta perspectiva es compartida con Blanco (1995), resaltando el interaccionismo simbólico de la persona a medida que interacciona activamente en un contexto socio-cultural ante una realidad, produciendo un esquema dinámico de sus procesos mentales y comportamientos o estrategias según el cambio en el contexto socio-cultural, son representantes de esta propuesta Backman, 1964; Eiser, 1989, Rodríguez, 1991 (citados por Macías, Orozco, Amarís y Zambrano, 2013). 
Tabla 13. Análisis Factorial con rotación Varimax. Estrategias de Afrontamiento Individual

\begin{tabular}{|c|c|c|c|c|c|c|}
\hline & \multirow{2}{*}{$\begin{array}{l}\text { Estrategias de } \\
\text { afrontamiento }\end{array}$} & \multirow{2}{*}{ Items } & \multicolumn{4}{|c|}{ Matriz de Componentes Rotados } \\
\hline & & & 1 & 2 & 3 & 4 \\
\hline \multirow{38}{*}{ 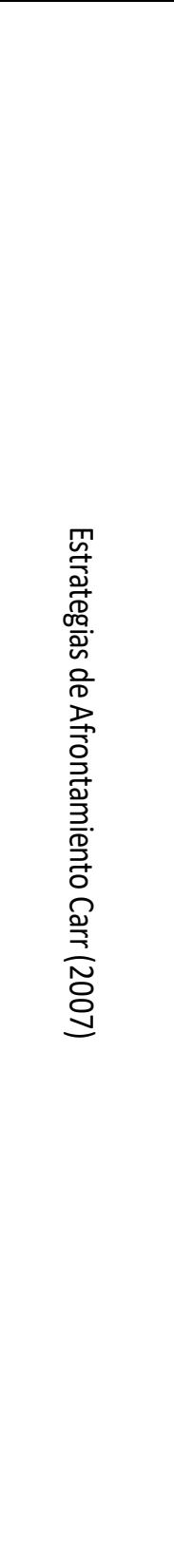 } & \multirow{15}{*}{ 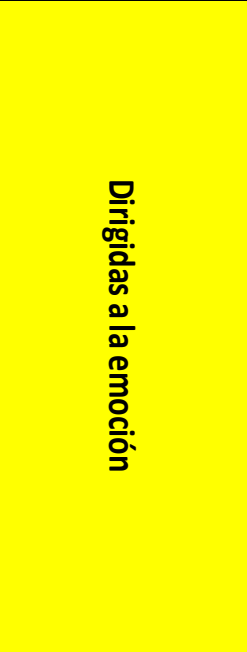 } & P1 & .660 & & & \\
\hline & & P2 & .696 & & & \\
\hline & & P3 & .697 & & & \\
\hline & & P4 & .672 & & & \\
\hline & & P8 & .673 & & & \\
\hline & & P9 & .696 & & & \\
\hline & & P10 & .651 & & & \\
\hline & & P11 & .698 & & & \\
\hline & & P12 & .628 & & & \\
\hline & & P15 & .612 & & & \\
\hline & & P16 & .605 & & & \\
\hline & & P17 & .611 & & & \\
\hline & & P18 & .539 & & & \\
\hline & & P19 & .713 & & & \\
\hline & & P31 & .561 & & & \\
\hline & \multirow{15}{*}{ 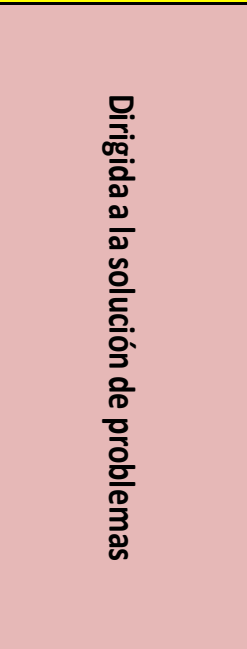 } & P5 & & .509 & & \\
\hline & & P6 & & .512 & & \\
\hline & & P7 & & .588 & & \\
\hline & & P13 & & .455 & & \\
\hline & & P14 & & .573 & & \\
\hline & & P21 & & .524 & & \\
\hline & & P22 & & .721 & & \\
\hline & & $\mathbf{P 2 5}$ & & .624 & & \\
\hline & & P27 & & .650 & & \\
\hline & & P29 & & .681 & & \\
\hline & & P30 & & .703 & & \\
\hline & & P33 & & .739 & & \\
\hline & & P36 & & .541 & & \\
\hline & & P37 & & .704 & & \\
\hline & & P38 & & .745 & & \\
\hline & \multirow{8}{*}{ 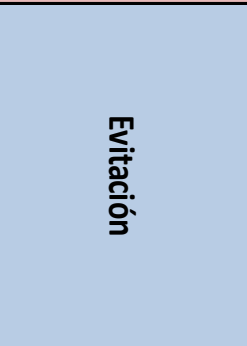 } & P23 & & & .480 & \\
\hline & & P24 & & & .660 & \\
\hline & & P26 & & & .652 & \\
\hline & & P32 & & & .582 & \\
\hline & & P34 & & & .481 & \\
\hline & & P35 & & & .520 & \\
\hline & & P39 & & & .624 & \\
\hline & & P40 & & & .613 & \\
\hline \multirow{3}{*}{$\begin{array}{l}\text { González, } \\
\text { et al (2015) }\end{array}$} & \multirow{3}{*}{ 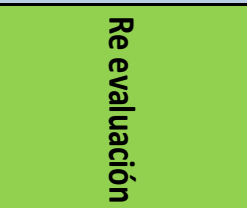 } & P20 & .526 & & .353 & .424 \\
\hline & & & & & & \\
\hline & & P28 & & .427 & .304 & .672 \\
\hline
\end{tabular}

Fuente: González, Ortega, Castillo, Whetsell, Cleghorn (2015). Información derivada de la aplicación del Inventario de Estrategias de Afrontamiento, durante el estudio. 
Los resultados del análisis factorial del Inventario de estrategias de afrontamiento para este estudio demuestra:

1. No confirma la estructura primaria del constructo en relación con el estudio de Tobin et al; (1989) y el estudio de Cano, Rodríguez, García (2007)

2. Identifica una estructura con cuatro componentes: Estrategias de afrontamiento dirigido a la emoción, Estrategias de afrontamiento dirigido a la solución de problemas, Estrategias de Afrontamiento de Evitación, Estrategias de Afrontamiento de Reevaluación. Tabla 13

3. Evidencia un comportamiento diferente para los ocho factores o estrategias de afrontamiento, Basándonos en la frecuencia de utilización de las estrategias para cada componente, como se muestra en la tabla 14

Tabla 14. Estrategias de afrontamiento según frecuencia de utilización de los factores en la estructura primaria: Estrategias de Afrontamiento Individual

\begin{tabular}{|l|c|c|c|c|c|c|c|c|c|}
\hline \multirow{2}{*}{$\begin{array}{c}\text { Estrategias de } \\
\text { Afrontamiento }\end{array}$} & $\begin{array}{c}\text { Resolución de } \\
\text { problema }\end{array}$ & Autocritica & $\begin{array}{c}\text { Expresión } \\
\text { emocional }\end{array}$ & $\begin{array}{c}\text { Pensamiento } \\
\text { desiderativo }\end{array}$ & $\begin{array}{c}\text { Retirada } \\
\text { social }\end{array}$ & $\begin{array}{c}\text { Evitación de } \\
\text { Problema }\end{array}$ & $\begin{array}{c}\text { Reestructuración } \\
\text { cognitiva }\end{array}$ & $\begin{array}{c}\text { Apoyo } \\
\text { emocional }\end{array}$ & Total \\
\hline Dirigido a la emoción & 3 & 3 & 3 & 2 & 2 & 2 & - & - & 15 \\
\hline Dirigido a la solución & 2 & - & 1 & 1 & - & 1 & 5 & 5 & 15 \\
\hline $\begin{array}{l}\text { Estrategias de } \\
\text { Evitación }\end{array}$ & & 2 & 1 & & & & & & - \\
\hline Reevaluación & - & - & - & 2 & - & & - & - & 2 \\
\hline
\end{tabular}

Fuente: González, Cleghorn, Ortega-Gómez, Castillo y Whetsell (2015). Información derivada de la aplicación del Inventario de Estrategias de Afrontamiento, durante el estudio.

\section{Discusión}

En el estudio no se logra la estructura primaria como producto del análisis factorial, se obtienen cuatro componentes en la estructura 1. El primero y segundo componente con 6 factores cada uno y el tercero con 4 factores y el cuarto un factor esta variabilidad en la utilización de los factores o estrategias de afrontamiento, pone de manifiesto:

1.Los ajustes que realiza la persona como respuesta a la dinámica interacción entre este y su entorno sociocultural para alcanzar su adaptación a través de estrategias efectivas. Macías et al; (2013) señala que investigadores como Anarte, Ramiréz, López y Esteve, 2001; Galán y Perona, 2001; Zeinder y Endler, 1996 y Carr 2007, indican que la estrategia de afrontamiento individual presenta tres características en su clasificación:

1. Valoración, búsqueda del significado del suceso;

2. El problema, busque confrontar la realidad, maneja consecuencias;

3. La emoción regulación de aspectos emocionales.

4. En su análisis de instrumento que miden las estrategias de afrontamiento, Carr (2007), identifica estrategias de afrontamiento dirigido a la emoción, estratego de afrontamiento dirigido a la solución del problema y estrategias de afrontamiento dirigidas a la evitación, estas características, basadas en los comportamientos dinámicos de las personas al interactuar con su contexto y manifestadas a través de las estrategias de afrontamiento permiten explicar la estructura que emerge del análisis factorial. 
El nombre de estrategias individuales se sustenta en la propuesta de Lazarus y Folkman (1986), quienes vislumbran la estrategia de afrontamiento como producto de la interacción recíproca de la persona y su contexto y la rutina que demanda de la persona la toma de decisiones. La perspectiva de Blanco, A. (1995), quien resalta el interaccionismo simbólico de la persona a medida que interacciona activamente en un contexto socio-cultural ante una realidad, produciendo un esquema dinámico de sus procesos mentales y comportamientos o estrategias según el cambio en el contexto socio-cultural, son representantes de esta propuesta Backman, 1964; Eiser, 1989, Rodríguez, 1991, citados por Macías, Orozco, Amarís y Zambrano, 2013).

\section{Conclusiones}

El estudio actual no confirma la estructura primaria del constructo en relación con el estudio de Tobin et al; (1989) y el estudio de Cano, Rodríguez, García (2007). La confiabilidad del instrumento en el contexto de Panamá presenta fiabilidad excelente ( 0,930), el análisis factorial de la adaptación española del Inventario de estrategias de afrontamiento versión española adaptada de Cano, Rodríguez, García (2007), detecta una estructura primaria con cuatro componentes, que debido a la estrategia que lo compone su reagrupación y frecuencia de aparición y sustentado en fundamentos conceptuales y teóricos presentados en la propuesta de Lazarus y Folkman (1989) y Blanco, A; (1995), citados por Macías (2013), se le denomina a esta estructura 1, "Estrategias de afrontamiento individual".

Según la clasificación propuesta por Carr (2007), Lazarus y Folkman (1989), Anate, Ramírez, López y Esteve; 2001), citados por Macías (2013), los cuatro componentes de la estructura en su orden de aparición se dividen en: -Estrategias de afrontamiento dirigida a la emoción, -estrategias de afrontamiento dirigido a la solución de problemas, - estrategias de afrontamiento dirigidos a la evitación y estrategias de afrontamiento dirigida a la reevaluación.

\section{Referencias:}

Bernal, Carolina; Lemos Mariantonia; Medina Luis; Ospina, Jorge; Torres, Yolanda. (2009).

Estrategias de afrontamiento y presión arterial. CES Psicología, 2(2); julio-diciembre 2009. P 49-59.

Medellín, Colombia. Recuperado de: http://www.redalyc.org/pdf/4235/423539413004.pdf

Cano Gracia, F, J; Rodríguez Franco, L.; García Martínez, J. (2007). Adaptación española del Inventario de Estrategias de Afrontamiento. Actas Española de Psiquiatría. España. 35(1):29-39. Recuperado de: https://personal.us.es/fjcano/drupal/files/AEDP\%2007\%20(esp).pdf

Carr, A, (2007). Psicología positiva. Barcelona, editorial Paidós. Recuperado de: http://www.fundacionforo.com/pdfs/psicopositiva-programa.pdf

Castaño, Elena; León del Barco, Benito (2010). Estrategias de Afrontamiento del Estrés y Estilos de Conducta Interpersonal. International Journal of Psychology an Psychology Therapy. 2010 10(2). Junio p. 245-257. Recuperado de: http://www.redalyc.org/pdf/560/Resumenes/Abstract_56017095004_2.pdf

Carretero H, Pérez C. (2005). Normas para el Desarrollo y Revisión de Estudios Instrumentales. International Journal of Clinical and Health Psychology; 2005; 5(3):521-551. Recuperado de: http://www.aepc.es/ijchp/articulos_pdf/ijchp-158.pdf 
Carvajal, A; Centeno, C; Watson, R; Martínez, M; Rubiales, A. S. (2011). ¿Cómo validar un Instrumento de Medida en Salud? Anales del Sistema Sanitario de Navarra. 34(1): 63-72 Núm. 1. Recuperado de: https://recyt.fecyt.es//index.php/ASSN/article/view/10317/8017

Folkman, S. (1984). Personal Control and Stress and Coping Processes: A Theoretical Analysis. US National Library of Medicine National Institutes of Health. 1984 Apr;46(4):839-52 Recuperado de:

https://www.ncbi.nlm.nih.gov/pubmed/6737195

Folkman, S., \& Lazarus, R. S. (1980). An Analysis of Coping in a Middle-aged Community Sample. Journal of Health and Social Behavior, 21(3), 219-239. doi: 10.2307/2136617. Recuperado de: https://www.jstor.org/stable/2136617?seq=1\#page_scan_tab_contents

George, D., \& Mallery, P. (2003). SPSS for Windows Step by Step: A Simple Guide and Reference. 11.0 Update (4th ed.). Boston: Allyn \& Bacon. 231. Recuperado de:

https://books.google.com.pa/books/about/SPSS_for_Windows_Step_by_Step.html?id=AghHAAAAMAAJ\&r edir_esc=y

González Y. (2008). Evaluación de la Eficacia del cuidado como Intervención Terapéutica: un Programa Educativo con enfoque Cognitivo. Tesis Doctoral. Universidad Nacional de Colombia. Recuperado de: http://www.scielo.org.co/scielo.php?script=sci_nlinks\&ref=000157\&pid=S1657$5997201300020000300017 \& \operatorname{lng}=\mathrm{es}$

Lazarus, Richard; Folkman, Susan. (1986). Estrés y Procesos Cognitivos. 2da Edición, Ediciones Martínez Roca, S.A. España. ISBN: 84-270-1013-3. Recuperado de: https://dialnet.unirioja.es/servlet/libro?codigo $=222981$

Luján Tangarife, S. A., Cardona Arias, J. A. (2015). Construcción y Validación de Escalas de Medición en Salud: Revisión de Propiedades Psicométricas. Archivos de Medicina. 11(3:7); 2015, 1-7. Recuperado de: http://www.archivosdemedicina.com/medicina-de-familia/construccin-y-validacin-de-escalasde-medicin-ensalud-revisin-depropiedades-psicomtricas.php?aid=6694

Macías Amaris, María; Camilo Orozco; Marcela Amarís; Javier Zambrano. (2013). Estrategias de Afrontamiento Individual y Familiar Frente a Situaciones de Estrés Psicológico. Revista Online Psicología desde el Caribe, 30(1): enero a abril 2013. Recuperado de:

http://rcientificas.uninorte.edu.co/index.php/psicologia/article/view/2051/6906

Martínez, Agustín; José Piqueras; Candido Inglés. (2012). Relaciones entre Inteligencia Emocional y Estrategias de Afrontamiento ante el Estrés. Depto. de Psicología de la Salud, Universidad Miguel Hernández Elche, Alicante. Recuperado de: http://reme.uji.es/articulos/numero37/article6/article6.pdf

Morán, Consuelo; Landero, René; González, Mónica. (2009). COPE-28: un Análisis Psicpmétrico de la Version en Español del Brief COPE. Universitas Psychologica, 9 (2), 543-552; Bogotá, Agosto 2009.

Recuperado de: http://pepsic.bvsalud.org/scielo.php?script=sci_arttext\&pid=S1657$92672009000200020 \& \operatorname{lng}=$ pt\&tlng=es.

Nava Quiroz, Carlos; Ollua Méndez, Patricia; Vega Valero, Cynthia; Soria Trujano, Rocio. (2010). Inventario de Estrategias de Afrontamiento: una Replicación. Psicología y Salud; 20 (2); 213-220. JulioDiciembre 2010. Recuperado de: http://revistas.uv.mx/index.php/psicysalud/article/view/604/1048

Paniagua, Ramón. (2015). Metodología para la Validación de una Escala o Instrumento de Medida. Universidad de Antioquia, Facultad de Salud Pública, Colombia. 2015. Recuperado de:

http://www.udea.edu.co/wps/wcm/connect/udea/d76a0609-c62d-4dfb-83dc5313c2aed2f6/METODOLOG\%C3\%8DA+PARA+LA+VALIDACI\%C3\%93N+DE+UNA+ESCALA.pdf?M $\mathrm{OD}=\mathrm{AJPERES}$ 
Pascual, Aitziber; Susan Conejero; Itziar Etxebarria (2017). ¿Existen Estrategias de Afrontamiento y de Regulación Emocional más Adecuadas que Otras? Consejo General de la Psicología de España. INFOCOPONLINE. 2017. Recuperado de: http://www.infocop.es/view_article.asp?id=6650\&cat=50

Pascual, Aitziber; Susan Conejero; Itziar Etxebarria (2016). Coping Strategies and Emotion Regulation in Adolescents: Adecuacy and Gender Differences. Ansiedad y Estrés. Enero-Junio 201622 (1), Recuperado de: http://www.elsevier.es/es-revista-ansiedad-estres-242-articulo-coping-strategies-emotion-regulation-inS1134793716300070

Ramada Rodilla, J. M; Serra Puadas, C; Delciós Clanchet, G. L. (2013). Adaptación Cultural y Validación de Cuestionarios de Salud: Revisión y Recomendaciones Metodológicas. Salud Pública Mexicana, 2013, 55(1), 57-66 Recuperado de: http://www.medigraphic.com/pdfs/salpubmex/sal-2013/sal131g.pdf

Rexrode, K, R; Petersen, S; O’Toole, S. (2007). The Ways of Coping Scale. Educational and Psychological Measurement, 68(29, 262-280. Recuperado de: http://journals.sagepub.com/doi/abs/10.1177/0013164407310128

Rodríguez, Francisco; Estrada, Cristina; Rodríguez, Luis; Bringas, Carolina. (2014). Adaptación del Inventario de Estrategias de Afrontamiento (CSI) a la Población Penitenciaria de México. Psychology/Psicología Reflexăo e Critica, 27(3), 415-423. Recuperado de: http://www.scielo.br/scielo.php?pid=S0102-79722014000300415\&script=sci_abstract\&tlng=es

Roy, Callista. (2004). Coping and Adaptation Processing Scale Development and Testing. William F. Connel School of nursing. Boston College. Chesnut Hill, MA. Manuscrip, 2004. Recuperado de: http://www.scielo.org.co/scieloOrg/php/reflinks.php?refpid=S1657$5997200700010000500001 \& \operatorname{lng}=$ pt\&pid=S1657-59972007000100005

Roy, Callista. (2009). The Roy Adaptation Model, Third Edition. Pearson Education, Inc; Upper Saddle River, New Jersey. 2009. p.1- 553. Recuperado de: https://www.amazon.com/Roy-Adaptation-Model3rd/dp/0130384976

Rubio, Laura; Dumitrache, Cristina; Cordón-Pozo, Eulogio; Rubio-Herrera, Ramona. (2016). Psychometric Properties of the Version of the Coping Strategies Inventory (CSI) in Older People. Revista Anales de Psicología, 2016. 32, (2), mayo. 355- 365. Recuperado de: http://scielo.isciii.es/scielo.php?script=sci_abstract\&pid=S0212-97282016000200007

Sánchez, Ricardo; Echeverry, Jairo. (2014). Validación de Escalas de Medición en Salud. Salud Pública. 2004, 6(3):302-316. Recuperado de: http://www.scielosp.org/scielo.php?pid=S012400642004000300006\&script=sci_abstract\&tlng=es

Urrego Betancourt, Yaneth; Aragón Meza, Alejandra; Combita Suarez, Julie; Mora Quintero, Mónica. (2012). Descripción de las Estrategias de Afrontamiento para Padres con Hijos con Discapacidad Cognitiva. Psicología con Éxitos. Universidad Piloto de Colombia, Programa de Psicología. Recuperado de: http://www.contextos-revista.com.co/Revista\%208/A3DescripciOn\%20de\%20las\%20estrategias\%20de\%20afrontamiento\%20para\%20padres\%20con\%20hijos\%20 con\%20discapacidad\%20cognitiva.pdf 
INVENTARIO DE ESTRATEGIAS DE AFRONTAMIENTO por Cano, Rodríguez y García, 2007 con ajustes inquietico para el contexto de Panamá Redistribuido según factor por González Y; Ortega, E; Castillo,R; Whetsell, M; Cleghorn, D .(2015). Estrategias Primarias.

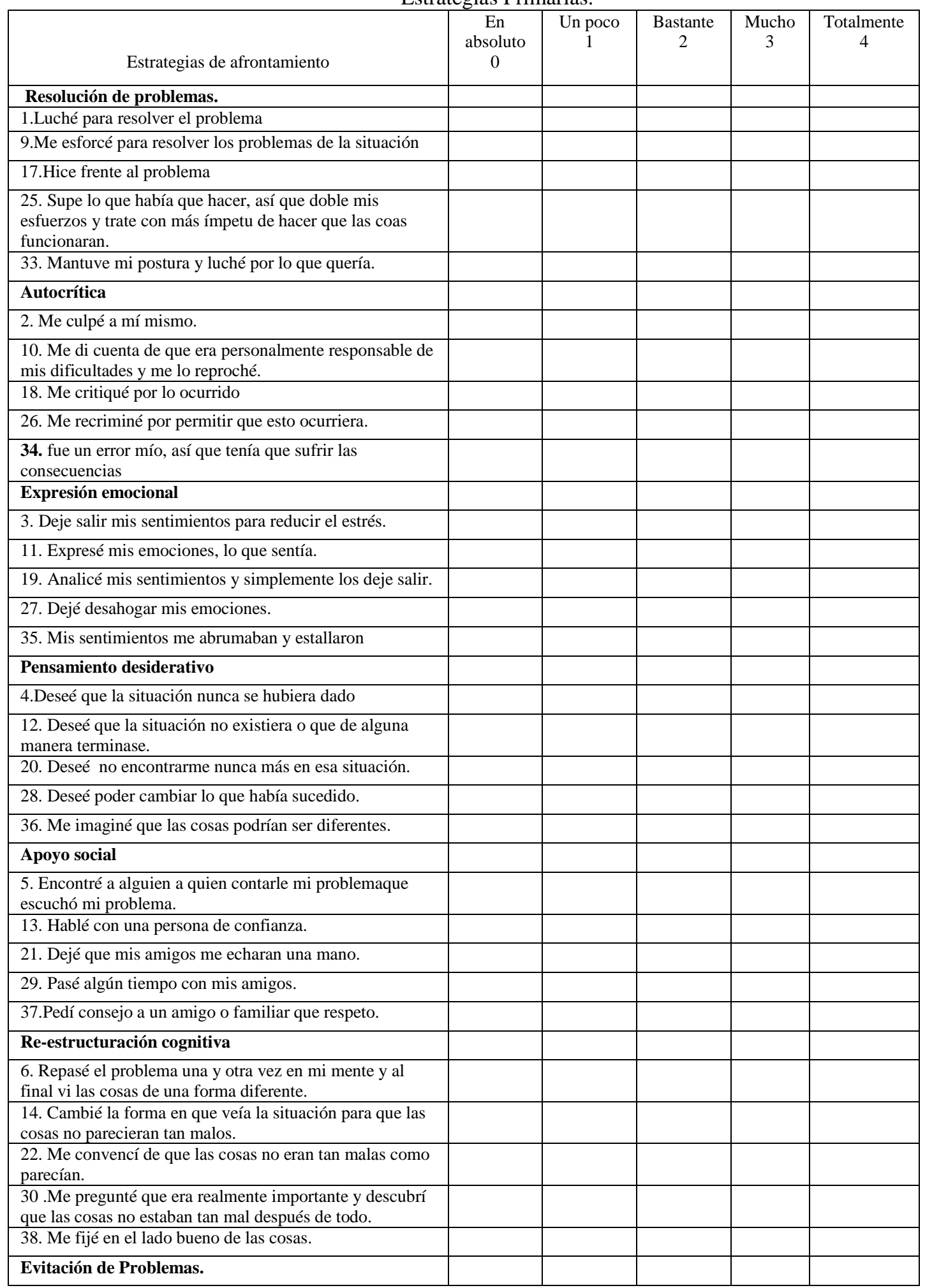


Enfoque, Revista Científica de Enfermería, VOL. XXI, N 17 Julio a Diciembre 2017 ISSN 1816-2398 Impreso

\begin{tabular}{|l|l|l|l|l|l|}
\hline $\begin{array}{l}\text { 7. No dejé que me afectara; evité pensar en ello } \\
\text { demasiado. }\end{array}$ & & & & & \\
\hline 15. Traté de olvidar por completo el asunto. & & & & & \\
\hline $\begin{array}{l}\text { 23. Quité importancia a la situación y no quise } \\
\text { preocuparme más. }\end{array}$ & & & & & \\
\hline 31. Me comporté como si nada hubiera pasado. & & & & & \\
\hline 39. Evité pensar o hacer nada. & & & & & \\
\hline Retirada social & & & & & \\
\hline 8. Pasé algún tiempo solo. & & & & & \\
\hline 16. Evité estar con gente. & & & & & \\
\hline 24. Oculté lo que pensaba y sentía. & & & & & \\
\hline 32. No dejé que nadie supiera como me sentía. & & & & & \\
\hline 40. Traté de ocultar mis sentimientos. & & & & & \\
\hline Grado de eficacia percibida del afrontamiento & & & & & \\
\hline 41. me consideré capaz de afrontar la situación. & & & & & \\
\hline
\end{tabular}

Recibido: 29 de Octubre 2017

Aprobado: 30 de Noviembre 2017 